\title{
Mechanism of variations in environmental magnetic proxies of lake sediments from Nam Co, Tibet during the Holocene
}

\author{
SU YouLiang ${ }^{1,3}$, GAO Xing $^{2 *}$, LIU QingSong ${ }^{3}$, HU PengXiang $^{3}$, DUAN ZongQi $^{3}$, \\ JIANG ZhaoXia ${ }^{3}$, WANG JunBo ${ }^{1}$, ZHU LiPing ${ }^{1}$, DOBERSCHÜTZ Stefan ${ }^{4}$, \\ MÄUSBACHER Roland ${ }^{4}$, DAUT Gerhard ${ }^{4} \&$ HABERZETTL Torsten ${ }^{4}$ \\ ${ }^{1}$ Key Laboratory of Continental Collision and Plateau Uplift, Institute of Tibetan Plateau Research, Chinese Academy of Sciences, \\ Beijing 100085, China; \\ ${ }^{2}$ State Key Laboratory of Resources and Environmental Information System, Institute of Geographic Sciences and Natural Resources Research, \\ Chinese Academy of Sciences, Beijing 100101, China; \\ ${ }^{3}$ State Key Laboratory of Lithospheric Evolution (SKL-LE), Institute of Geology and Geophysics, Chinese Academy of Sciences, \\ Beijing 100029, China; \\ ${ }^{4}$ Institut für Geographie, Friedrich-Schiller-Universität, Jena D-07743, Germany
}

Received April 18, 2012; accepted May 21, 2012; published online March 6, 2013

\begin{abstract}
High-resolution environmental records from the Tibetan Plateau are essential to understand past global climatic and environmental changes. Magnetic minerals in lake sediments are important proxies to reconstruct environmental and climatic changes. Nam Co (lake) is a typical great lake in the transitional region of southwest monsoon in the Tibetan Plateau. Previous studies have extensively focused on geochemistry, microfossils, sedimentology and biochemistry analysis of Nam Co, which provides sound interpretation of paleoclimatic and paleoenvironmental changes. However, up to now, no systematic environmental magnetic studies have been carried out. Therefore, high-resolution and systematic magnetic studies combined with geochemical parameters were carried on lake sediments of core NC 08/01 from Nam Co for the Holocene period (11.3 cal ka BP) in order to explore how magnetic properties of the sediments respond to climatic changes. Based on variations of magnetic proxies, the sequence can be separated into 3 units. Unit $1(236-199 \mathrm{~cm}, 11.3-7.8 \mathrm{cal} \mathrm{ka}$ BP) contains dominantly coarse-grained magnetite with homogeneous grain size. A positive correlation between magnetite and Ti strongly suggests that these coarse-grained detrital magnetites reflect detrital input signals due to insignificant effects of postdepositional dissolution processes on these coarse-grained magnetite particles. For Unit 2 (198-102 cm, 7.8-2.1 cal ka BP), magnetic grain size is finer and the corresponding concentration of magnetite is also reduced. This is mainly due to significant dissolution of these fine-grained detrital magnetite particles, which were transported under reduced water flow conditions during this period. For Unit $3(101-0 \mathrm{~cm}, 2.1-0$ cal ka BP), the bulk magnetic properties are dominated by a mixture of single domain biogenic magnetite and detrital magnetite. The concentration of magnetic minerals is not correlated with the Ti content. In conclusion, the preservation of magnetic minerals in the lake sediment and thus the corresponding magnetic properties are related to the initial grain size. Combination of magnetic properties (including variation of grain size and concentration) and other proxies of detrital inputs (e.g. Ti) can be used to infer the variation of redox conditions in Nam Co. These results provide a viable framework for reconstructing the paleoenvironmental changes of this lake.
\end{abstract}

lake sediment, rock magnetism, Nam Co, Tibetan Plateau, Holocene

Citation: Su Y L, Gao X, Liu Q S, et al. Mechanism of variations in environmental magnetic proxies of lake sediments from Nam Co, Tibet during the Holocene. Chin Sci Bull, 2013, 58: 1568-1578, doi: 10.1007/s11434-012-5324-7

The Tibetan Plateau (TP) is known as the "Third Pole", highlighting its significance for the global climate. It is

*Corresponding author (email: gxing@igsnrr.ac.cn) strongly influenced by the Westerlies, Indian Ocean and East Asian Summer Monsoon [1]. The lakes in TP form a huge plateau lake zone, which is the highest and the largest in area lake zone on Earth. Lake sediments are important 
archives to record high-resolution, sensitive and continuous paleoclimatic signals on continents [2,3]. Knowledge of Holocene climate variations is particularly important for the prediction of future climate scenarios and the development of human society. The latest studies revealed that abrupt shifts punctuated what is conventionally thought to have been a relatively stable Holocene climate, which is important to the global climatic dynamics [4]. Up to now, several lake sediment studies in the TP covering Holocene have been carried out using geochemical, biochemical and sedimentological methods. Among which, pollen, total organic carbon, grain size and microelements are important proxies to reveal that Holocene climate in the TP deteriorated from warm and wet to cold and dry within certain periods, and also with periodically abrupt shifts $[2,3]$.

Magnetic properties are proxies [5] that are popular due to their fast, economical, non-destructive and highly sensitive measuring techniques. In addition, magnetic properties, which are characterizing type, concentration and grain size distribution of magnetic minerals, have become important tools in reconstructing high-resolution paleoclimatic and paleoenvironmental records on lacustrine sediments [6]. Thouveny et al. [7] found that the susceptibility curve of Maar lake sediments in central France since 140 ka is correlated with the oxygen isotopic curve of Greenland ice core on millennial scale, and thus the magnetic susceptibility can be treated as a proxy of paleoclimate. Environmental magnetic parameters have already been tested in paleoclimatic reconstruction based on lacustrine sediments on the TP. Zhu et al. [8] reconstructed the paleoclimate of Chen Co for the last 1400 year based on environmental magnetic studies, with consistent results in the climatic record for the same period from other parts of the TP. Mischke and Zhang [9] used volume magnetic susceptibility and frequencydependent susceptibility as proxies of detrital input flux to characterize six cold events in Ximen Co district during the Holocene.

Complexities exist in how the magnetic signals of lake sediments respond to climatic and environmental changes. On one hand, the mechanism of magnetic response to climatic and environmental changes in different lakes of the same area may differ due to factors such as catchment area, morphology, lithology, land surface plants cover, lake area, biotic and chemical condition of lake water. On the other hand, many processes that influence the sedimentation in a lake, such as detrital input variation, redox condition and biotic effect, often make it difficult to disentangle the magnetic response to environmental changes $[10,11]$. In addition, reductive diagenetic processes are prominent factors for altering magnetic signals by dissolving and reforming magnetic particles in two stages: iron oxide reductive or sulfate reductive stages, which depend on the supply of organic matter [12]. The diagenetic process only contains the iron oxide reductive stage when the amount of organic matter is low because detrital clastic iron oxides (e.g. magnetite) will be partly or completely dissolved through biogenetic processes in anoxic environment. However, diagenesis will continue into the sulfate reductive stage when sediments are enriched in organic matter. This is often accompanied by neoformation of authigenic ferrimagnetic iron sulfide, like greigite [12]. Among all of these factors, available Fe and S, as well as the redox conditions strongly constrain reductive diagenesis processes. A sedimentary environment with high input of organic matter can easily develop into an anoxic environment and cause reductive diagenesis. Jelinowask et al. [11] studied the magnetic properties of Lake Bledowo (Central Poland) for the Pleiocene and showed that abundant greigite formed during the initial lake formation; finer-grained magnetic minerals were preferentially dissolved by iron reducing bacteria, which resulted in an increase of the magnetic mineral grain size. Because the sensitivity of magnetic parameters respond to changes of postdeposional conditions it is not easy to apply magnetic proxies on paleoclimatic study without additional knowledge of the palaeoenvironment. Stockhausen and Thouveny [13] studied the sediment records of Lake Lac du Bouchet and two other lakes nearby in France and found that susceptibility measurements from the 3 lakes were difficult to match due to the local magnetite dissolution and additional dilution by non-magnetic minerals. Therefore, although magnetic properties of lake sediment are closely linked to climate changes, mechanism of variations in magnetic parameters should be clarified first when using magnetic parameters as climatic substituent proxies.

Nam Co is a typical great lake in the transitional region of southwest monsoon in the Tibetan Plateau and part of the great lake area in the southeast of North Tibet. Recently, there have already been some detailed reports on the variation of the lake sedimentology, chronology, growth and evolution of Nam Co [14]. Continuous high-resolution paleoenvironmental records, for the Holocene are mainly derived from lake sediments based on multi-proxy studies (Figure 1). Based on precise timescale and stratigraphic analysis, previous studies have extensively focused on geochemistry, microfossils, sedimentology and biochemistry analysis on Nam Co, which provides sound interpretation of paleoclimatic and paleoenvironmental changes [15,16]. These studies revealed that climate of the Nam Co region experienced a shift from warm and humid to cold and dry conditions $[17,18]$ during the Holocene, while the lake level has experienced a number of fluctuations $[3,19]$. However, up to now, no systematic environmental magnetic study has ever been carried out on Nam Co. Therefore, highresolution and systematic magnetic studies combined with geochemical and biological parameters were carried on sediments of Nam Co for the Holocene in order to explore how magnetic properties of the sediments respond to climatic changes, and to provide firm theoretical foundation for reconstructing long-scale paleoclimatic records on lake sediments based on environmental magnetic methods. 

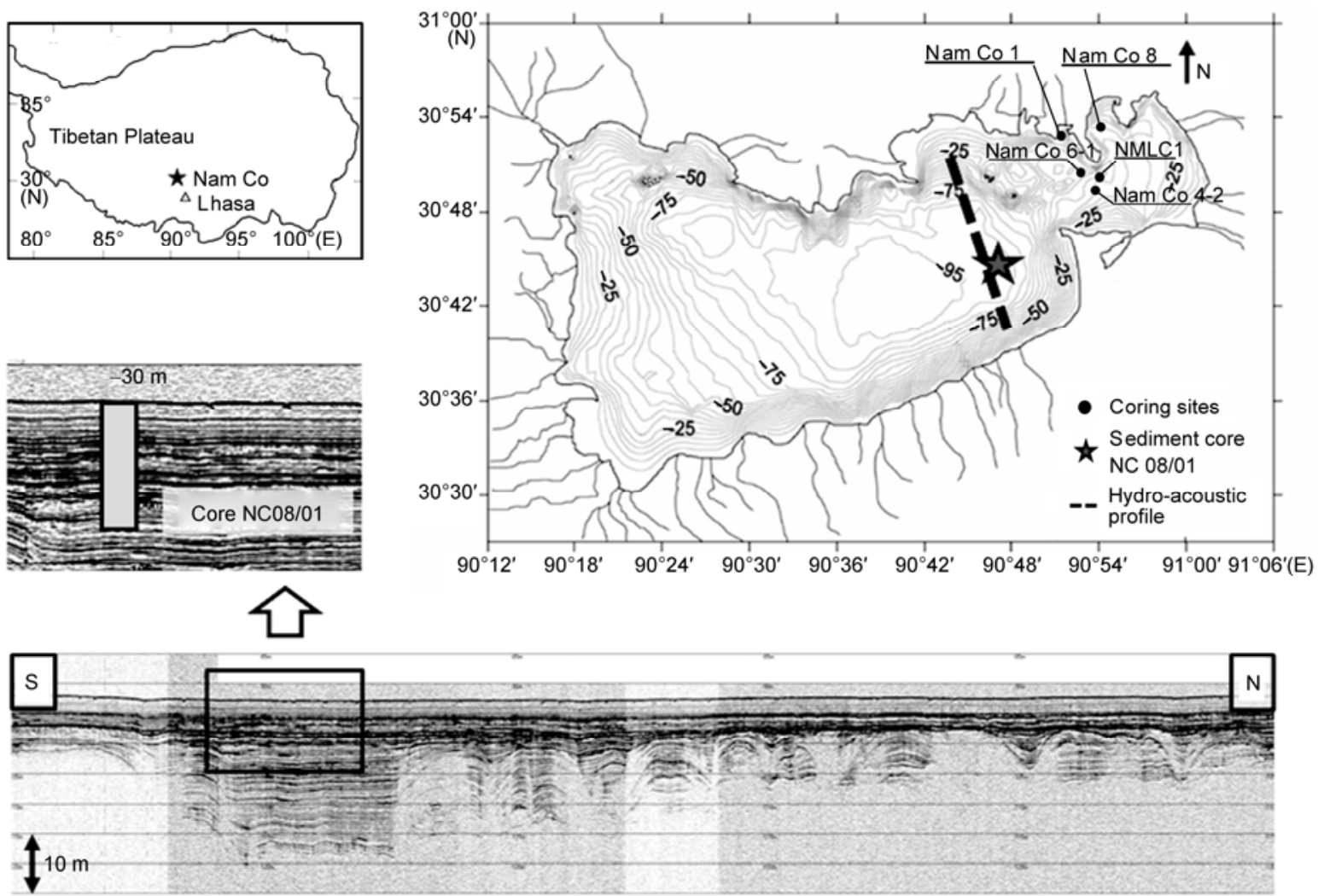

Figure 1 Location of Nam Co, Tibet and coring sites. The dashed line indicates the location of hydro-acoustic profile (from unpublished data of Doberschütz S).

\section{Study area}

Nam Co $\left(30.7^{\circ} \mathrm{N}, 90.7^{\circ} \mathrm{E}\right)$ is located in the central south region of the TP, north of the Nyainqentanglha range. It is the largest lake in Tibet and also the highest saltwater lake in the world (Figure 1). Nam Co has a closed elongated basin with two subbasins, $78 \mathrm{~km}$ in WS direction, $44 \mathrm{~km}$ in NS direction, a maximum water depth $98.9 \mathrm{~m}$ and a present day lake level at an elevation of $4718 \mathrm{~m}$. The basin is subdivided into two subbasins: a larger one in the west with a water depth exceeding $90 \mathrm{~m}$ and with a flat bottom and a smaller and shallower (max. $60 \mathrm{~m}$ ) northeastern basin [20]. The lakeshore deposits are mainly composed of silty clay sand, sand and sandy gravel, with Carboniferous-Permian slate on the south, Cretaceous sandstone, and siltstone and conglomerate on the north, south and west [22]. Nam Co is mainly supplied by atmospheric precipitation and glacial-melt water. Rivers are mainly distributed on west and south of the lake, with the largest one originating from Nyainqentanglha Mountain and entering the lake from southwest [21]. Nam Co shrunk during Holocene; however, it has grown in the last 30 years. The lake area was 1920 $\mathrm{km}^{2}$ measured in 1979 , and about $1980 \mathrm{~km}^{2}$ now. The catchment area of the lake is $10610 \mathrm{~km}^{2}$, with a replenish coefficient of $5.53[20,21]$. The climate of Nam Co area is a semi-arid subarctic plateau climate, with snow cover for 3 to 5 months each year. Both the temperature regime and the precipitation pattern favor permafrost conditions within the catchment [16].

\section{Coring and methods}

\subsection{Sediment coring}

The Sino-German research group recovered a sediment core $\mathrm{NC}$ 08/01 $1042 \mathrm{~cm}$ in length on the basis of hydro-acoustic profile results in a water depth of $93 \mathrm{~m}$ in the central basin in $2008\left(30.73^{\circ} \mathrm{N}, 90.78^{\circ} \mathrm{E}\right.$, Figure 1). The core composes of a piston core and a paralleled gravity core. In this study we focus on the Holocene deposit $(0-236 \mathrm{~cm}$ sediment depth). Sediments between 236-126 cm (11.3-3.0 ka) consist of silty clay with light greyish color containing a few dark greyish to anthracite spots; $126-104 \mathrm{~cm}(3.0-2.1 \mathrm{ka})$ composes of transitional zone of sand-clay; $104-0 \mathrm{~cm}$ $(2.1-0 \mathrm{ka})$ is characterized by clayey silt deposits. The color changes from light greyish to anthracite with light greyish spots. The sampling interval is $1 \mathrm{~cm}$.

\subsection{Sediment dating and depth-age curve}

The age-depth model for the studied time span is based on 15 AMS ${ }^{14} \mathrm{C}$ dates on core NC 08/01 $(0-236 \mathrm{~cm}$ sediment depth) and calibrated for a carbon reservoir effect based on the surface sediment. Accordingly, the age-depth curves of 
core NC 08/01 is established based on 9 reliable dates (Figure 2(j), from $[19,23])$.

\subsection{Methods}

Samples were dried at $38^{\circ} \mathrm{C}$, ground uniformly and then placed in an $8 \mathrm{~cm}^{3}$ plastic cubic box in the lab to conduct magnetic measurement: low frequency susceptibility $\left(\chi_{\mathrm{lf}}\right.$, mass normalized) of the samples is measured by Kappa Bridge multiple frequency susceptibility meter (MFK1-FA) produced by AGICO company (Czech Republic), the measured frequency is $976 \mathrm{~Hz}$ (F1). Subsequently, anhystereticremanence magnetization (ARM), isothermal remanence magnetization (IRM) for all samples and 3-axis thermal demagnetization for selected samples were measured by 2G-760 U-channel rock superconducting magnetometer in field-free room $(<300 \mathrm{nT})$. The peak alternative field to acquire ARM was $100 \mathrm{mT}$, the corresponding DC field was $50 \mu \mathrm{T}$. IRM was produced by $2 \mathrm{G}$ Enterprise pulse magnetization meter, in this study we term the IRM acquired at $1 \mathrm{~T}$ as SIRM. To study the high coercivity magnetic mineral in the samples in a quantitative way, we applied backward fields of 100 and $300 \mathrm{mT}$. The corresponding remanence magnetizations are termed as IRM $_{-100 \mathrm{mT}}$ and IRM $_{-300 \mathrm{mT}}$, respectively. We calculate the parameter for quantifying the absolute concentration of high coercivity magnetic minerals $\operatorname{HIRM}\left(\left(\right.\right.$ SIRM+IRM $\left.\left._{-300 \mathrm{mT}}\right) / 2\right)$ [5] and determine the $L$-ratio $($ HIRM/[(SIRM+IRM-100 mT)/2]) [24].

To systematically study the grain size and mineralogy of magnetic minerals in the samples, detailed rock magnetic measurements were done on selected samples. Hysteresis loops, IRM acquisition curves and backfield demagnetiza- tion curves were measured by vibrating samples magnetometer (VSM 3900) with a maximum field of $1 \mathrm{~T}$. Saturation magnetization $\left(M_{\mathrm{s}}\right)$, saturation remanence magnetization $\left(M_{\mathrm{rs}}\right)$, coercivity $\left(B_{\mathrm{c}}\right)$ and remanent coercivity $\left(B_{\mathrm{cr}}\right)$ were determined. First-order reversal curves (FORCs) were used to determine signals of magnetic domain and coercivity spectrum of samples [25]. FORCs were measured using VSM 3900 for selected samples with field increments of $1.17 \mathrm{mT}$. The FORC diagrams were calculated using the FORCinel software v1.18 [26]. Temperature-dependent susceptibility curves ( $\chi$ - $T$ curves) are effective in characterizing magnetic minerals in samples and alteration of minerals during heating processes [27]. Therefore, $\chi$ - $T$ curves were measured using Kappa Bridge MFK1-FA equipped with CS-3 temperature control system with a maximum temperature of $700^{\circ} \mathrm{C}$, and a temperature ramping rate of $2{ }^{\circ} \mathrm{C} / \mathrm{min}$ in argon environment to avoid samples being oxidized when heating. Low temperature magnetic analysis is effective in discriminating magnetic mineralogy of samples. In this study MPMS XL-5 magnetic measurement system was used to measure the zero-field-cool curves (ZFC) and field cool curves (FC). The detailed steps are as follows. Samples were cooled to $10 \mathrm{~K}$ in zero field and $2.5 \mathrm{~T}$, respectively, then SIRM acquired at $2.5 \mathrm{~T}$ was measured during warming up to $300 \mathrm{~K}$ in zero field with a temperature ramping rate of $5 \mathrm{~K} / \mathrm{min}$. In addition, temperature-dependent susceptibility curves of dual frequencies $1 \mathrm{~Hz}$ and $1500 \mathrm{~Hz}$ were measured in a weak field of $0.4 \mathrm{mT}$. Finally, 3-axis isothermal stepwise thermal demagnetization curves of selected samples were measured to discriminate magnetic carriers of different coercivity components [28]. Firstly, DC fields of 2.7 $\mathrm{T}, 0.5 \mathrm{~T}$ and $0.05 \mathrm{~T}$ were applied to samples in three

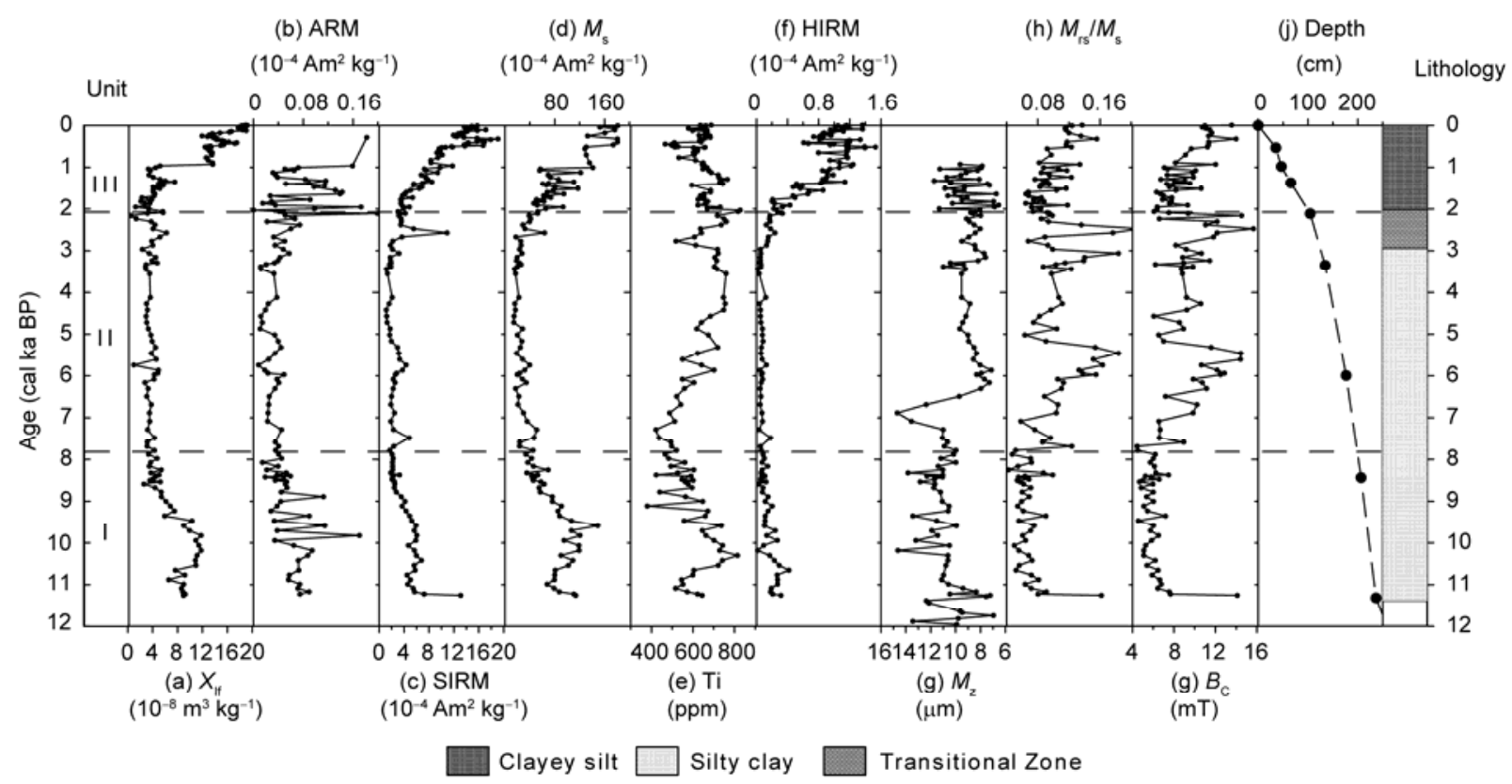

Figure 2 Variation of the magnetic properties, $M_{\mathrm{z}}$ (mean grain size for bulk sample) and Titanium of core NC 08/01 from Nam Co, Tibet since the Holocene, and the depth-age framework $\left(M_{\mathrm{z}}\right.$, Ti and depth-age model are from unpublished data of Doberschütz $\left.\mathrm{S}\right)$. 
orthogonal directions of $Z, Y$ and $X$, respectively to acquire corresponding IRM, then IRM after heated were measured up to $690^{\circ} \mathrm{C}$ with heating increments of $20-40^{\circ} \mathrm{C}$.

\section{Results}

\subsection{Variation of magnetic parameters with depth}

Variation of magnetic properties and $\mathrm{Ti}$ content of core $\mathrm{NC}$ 08/01 with age are shown in Figure 2. $\chi_{\mathrm{lf}}, \mathrm{SIRM}$ and $M_{\mathrm{s}}$ are often used to indicate the concentration of magnetic minerals. $M_{\mathrm{s}}$ is independent of grain size distribution apart from $\chi_{\mathrm{lf}}$ and SIRM [5]. Ti content is mainly controlled by terrigenous input [19]. The sequence can be divided into 3 units according to the variation of the three parameters mentioned above (Figure 2).

Unit $1(236-199 \mathrm{~cm}, 11.3-7.8 \mathrm{cal} \mathrm{ka} \mathrm{BP})$ : Variation of $\chi_{\mathrm{lf}}$, SIRM and $M_{\mathrm{s}}$ suggest that concentration of magnetic mineral increases upward first and then decreases, inconsistent with Ti changes. Low HIRM in Unit 1 indicates low concentration of high coercivity magnetic minerals. ARM indicates concentration of fine-grained ferrimagnetic minerals [5] and varies within Unit $1 . M_{\mathrm{rs}} / M_{\mathrm{s}}$ is an indicator for domain state of ferrimagnetic minerals (e.g. magnetite) [5], the value about $0.08(<0.1)$ suggested that samples are dominated by PSD sized grains [5]. $B_{\mathrm{c}}$ is low, about 4-8 $\mathrm{mT}$ and follows similar trend with $M_{\mathrm{rs}} / M_{\mathrm{s}}$, which further indicates the magnetic minerals are relatively coarse in this unit.

Unit 2 (198-102 cm, 7.8-2.1 cal ka BP): Overall, there is a decreasing trend from bottom to top in $\chi_{\mathrm{lf}}$, SIRM and $M_{\mathrm{s}}$, while Ti exhibits an increasing trend. The HIRM curve indicates that the concentration of high coercivity magnetic minerals is the lowest in this unit. In this unit ARM is significantly lower compared with Unit 1 , but it follows the same trend as $\chi_{\mathrm{lf}}, \mathrm{SIRM}$ and $M_{\mathrm{s}}$. The average of $M_{\mathrm{rs}} / M_{\mathrm{s}}$ and $B_{\mathrm{c}}$ of Unit 2 share an upward trend than Unit 1, and both show synchronous changes, which indicates that the grain size of the magnetic minerals start to become fine.

Unit $3\left(101-0 \mathrm{~cm}, 2.1-0\right.$ cal ka BP): $\chi_{\mathrm{lf}}$, SIRM and $M_{\mathrm{s}}$ have a similar increasing trend, while $\chi_{\mathrm{lf}}$ exhibits significant fluctuations. Ti content fluctuates around $625 \mathrm{ppm}$ with no clear correlation with magnetic parameters. HIRM exhibits a clear trend, which indicates high coercivity magnetic minerals in the sediment increase. In this unit, ARM is high with high amplitude fluctuations, which indicates strong variation in fine-grained magnetic minerals. $M_{\mathrm{rs}} / M_{\mathrm{s}}$ and $B_{\mathrm{c}}$ are low compared to Unit 2, but higher than Unit 1. As there is high concentration of high coercivity magnetic minerals in the unit, which will have significant influence in magnetic hysteresis parameters, the grain size of magnetic minerals in Unit 3 can not be unambiguously estimated.

\subsection{Magnetic properties}

Magnetic mineralogy of samples from core NC 08/01 was analyzed based on detailed rock magnetic techniques, including $\chi$ - $T$ curves, low temperature magnetic analysis, hysteresis loop, 3-axis thermal demagnetization curves, Day plot and FORC diagram. The results are shown as follows.

Unit 1: The hysteresis loop, uncorrected for paramagnetic contribution (Figure 3(k), dashed line), suggests obvious paramagnetic characteristics. The corrected hysteresis loop (Figure $3(\mathrm{k})$, solid line) starts to saturate at $0.2 \mathrm{~T}$, which indicates that soft magnetic minerals dominate the signal [5]. The $\chi-T$ heating curves of selected samples are shown in Figure 3(n). The susceptibility curves exhibits a slowly decreasing trend from room temperature to about $300^{\circ} \mathrm{C}$, which highlights the contribution of paramagnetic minerals [5]. The susceptibility increases slowly from 300 to $460^{\circ} \mathrm{C}$, which is probably related to the formation of magnetite from other minerals (such as Fe-bearing silicates, clay minerals) during heating [29]. The susceptibility slightly decreases from 460 to $550^{\circ} \mathrm{C}$. The sudden drop of susceptibility between $550-580^{\circ} \mathrm{C}$ matches Curie temperature of magnetite [5]. The remaining susceptibility after $680^{\circ} \mathrm{C}$ further indicates the presence of paramagnetic minerals. The sudden increase at about $580^{\circ} \mathrm{C}$ during cooling suggests abundant neoformation of magnetite during heating. In addition, the obvious peak at about $200-250^{\circ} \mathrm{C}$ during cooling indicates blocking behavior of iron sulfide [30]. The appearance of Verwey transition at about $120 \mathrm{~K}$ in low temperature susceptibility curves indicates presence of magnetite [31].

Unit 2: Similar to Unit 1, the hysteresis loop also indicates that the dominant magnetic carriers are soft magnetic minerals with a strong paramagnetic component. The slight decrease of susceptibility from room temperature to $180^{\circ} \mathrm{C}$ also indicates the presence of paramagnetic minerals. The susceptibility slightly increases from 180 to $280^{\circ} \mathrm{C}$, which is probably related to neoformation of strong magnetic minerals (e.g. pyrrhotite) transformed from sulfides during heating [32]. Then the susceptibility slowly decreases, the sudden drop of susceptibility during $550-580^{\circ} \mathrm{C}$ indicates Curie temperature of magnetite. The decreasing trend of susceptibility until $680^{\circ} \mathrm{C}$ indicates that a minor amount of hematite exists [5]. The sudden increase of susceptibility after $580^{\circ} \mathrm{C}$ during cooling suggests that magnetite formed during heating. In addition, the relatively wide blocking peak between $200-250^{\circ} \mathrm{C}$ during cooling suggests certain amount of sulfides exist [30]. No visible Verwey transition was found at $120 \mathrm{~K}$ in the low temperature magnetic curve (Figure 3(g) and (h)). The Verwey transition may be suppressed by the finer grain size and stronger oxidation state because the grain size of the unit is finer than Unit 1 [33]. Soft and intermediate coercivity components dominate the remanent magnetization of the sediment according to the 3 axis thermal demagnetization curves of selected samples (Figure 3(j) and (o)). Both components decrease quickly over the temperature interval between $200-300^{\circ} \mathrm{C}$ probably due to the presence of titanomagnetite or iron sulfides [28,32]. 

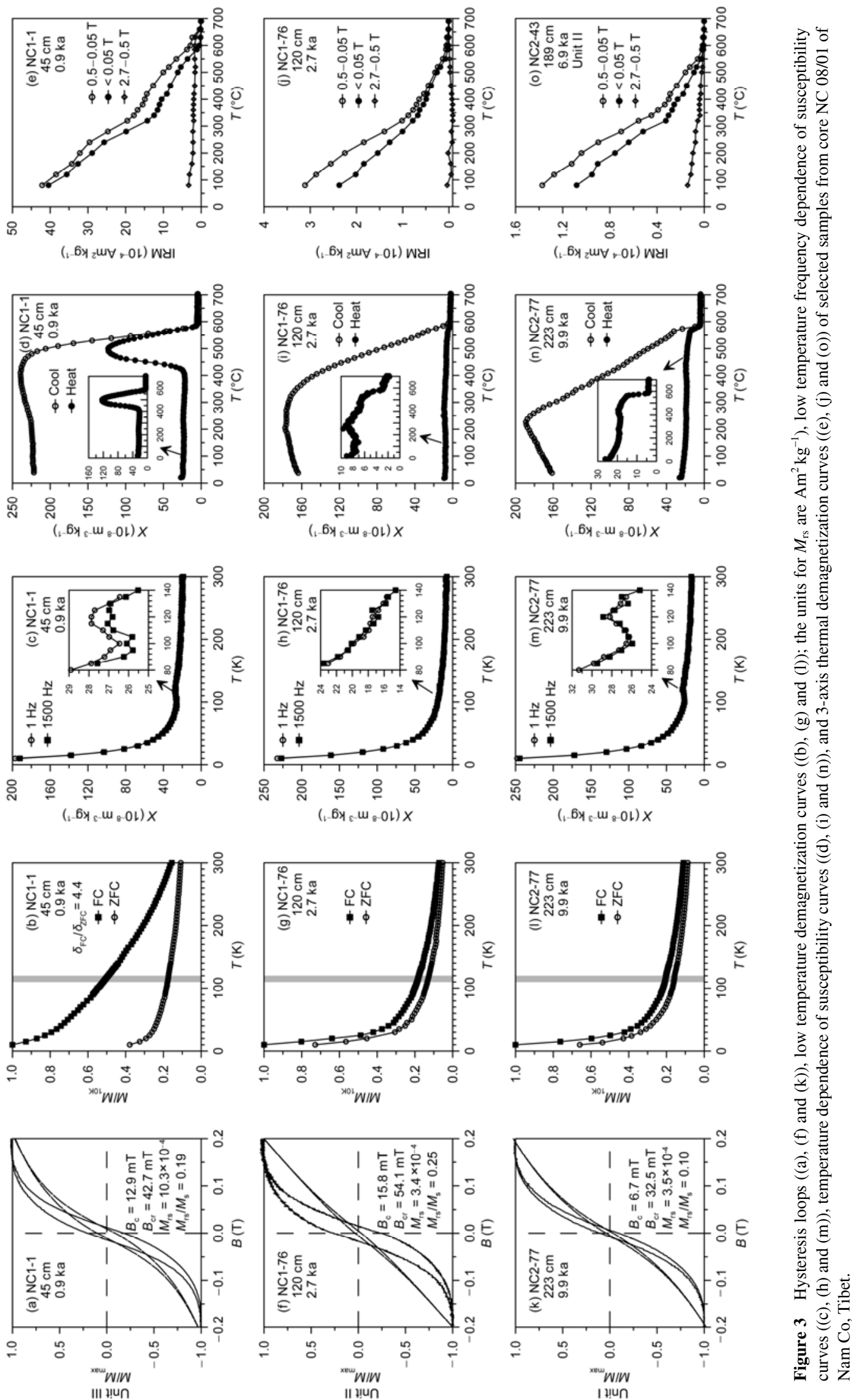
The remanent magnetization of the soft component tends to zero at $580^{\circ} \mathrm{C}$, which suggests that magnetite dominates the soft component. The remanent magnetization of high and medium components tends to zero at $650^{\circ} \mathrm{C}$, which confirms that hematite is the main high coercivity magnetic carrier.

Unit 3: The hysteresis loop exhibits similar behavior as the other two units, but with less contribution of paramagnetic minerals. Heating curve of $\chi-T$ curves indicates a slowly decreasing trend from room temperature to about $400^{\circ} \mathrm{C}$, which is associated to contribution of paramagnetic minerals (Figure 3(d). Susceptibility increases after $400^{\circ} \mathrm{C}$ then reaches a peak at about $500^{\circ} \mathrm{C}$, which is probably caused by the newly formed strong magnetic minerals during heating (e.g. Fe-bearing silicates, or clay minerals were transformed to magnetite during heating) [29]. Subsequently, $\chi_{\text {If }}$ drops quickly and reaches zero at $580^{\circ} \mathrm{C}$, which indicates that magnetite is the dominant magnetic carrier. The Verwey transition of magnetite can be observed in low temperature susceptibility curves (Figure 3(c)) [31]. However, in contrast to that of the selected samples of Unit 1
(Figure 3(m)), visible discrepancies exist between susceptibility of different frequencies in this unit (Figure 3(c)), which suggests that superparamagnetic particles contribute significantly to susceptibility at low temperature [5]. In addition, $\delta_{\mathrm{FC}} / \delta_{\mathrm{ZFC}}$ is $4.4(>2)$ in FC-ZFC curves (Figure 3(b)), which suggests that biogenic magnetite probably exists in these samples [34]. Three-axis thermal demagnetization curves of selected samples are consistent with results of $\chi-T$ curves (Figure 3(e), all results point to the presence of sulfide, magnetite and hematite).

Considering the grain size of magnetic minerals, hysteresis parameters $M_{\mathrm{rs}} / M_{\mathrm{s}}$ and $B_{\mathrm{cr}} / B_{\mathrm{c}}$ of selected samples were plotted on Day plot (Figure 4(c)) [35], with all samples locating in pseudo-single domain (PSD) zone. Samples of Unit 1 tend to locate in the coarse MD zone, consistent with FORC diagrams, which also display signals of MD particles [25]. Samples of Unit 2 have a wider distribution in Day plot, and shift upward compared to Unit 1, which indicates that the grain size becomes finer [25]. Peak coercivity field $\left(B_{\mathrm{c}, \text { FORC }}\right)$ of FORC diagram decreases (Figure 4(b)), which indicates the signal of PSD particles [25]. Most samples
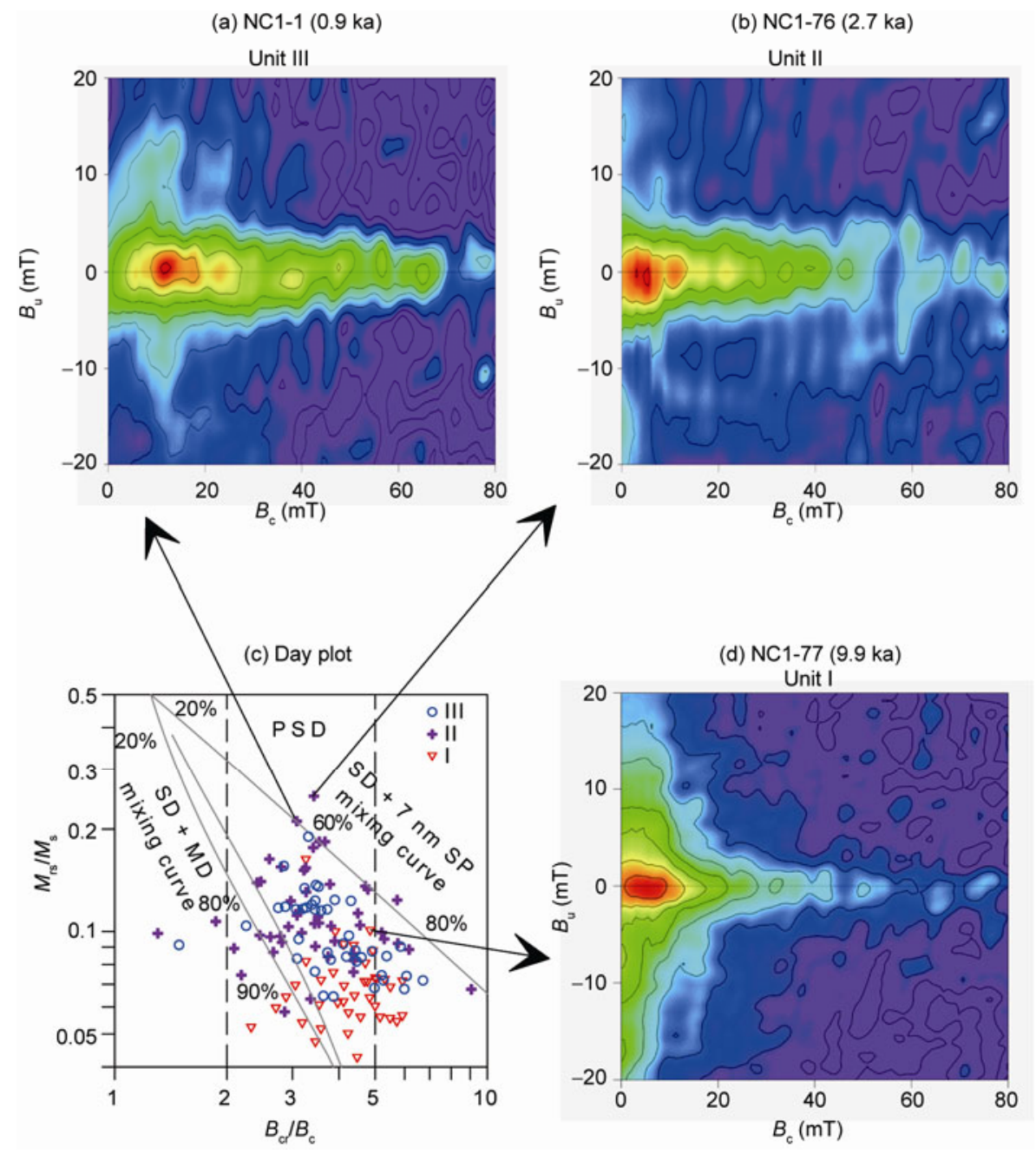

Figure 4 Day plot and FORC diagrams of selected samples from core NC 08/01 of Nam Co, Tibet, with a smoothing factor of 7 for FORC diagrams [26]. 
from Unit 3 are located in the mixing zone of SD and SP, $\mathrm{SD}$ and MD, respectively. FORC diagrams for selected samples of the unit display signal of mixture of SD and SP particles with narrow vertical distribution (Figure 4(a)), which indicates weak interaction between magnetic particles.

\subsection{Characteristics of magnetic minerals}

Low and intermediate components decrease obviously at about $300^{\circ} \mathrm{C}$ in 3-axis demagnetization curves (Figure 3(e), (j) and (o)) which indicates the presence of iron sulfides (probably minor amount of greigite contained in coarse pyrite particles [28,32]). Magnetite, hematite and greigite can co-exist in anoxic conditions, but this preservation depends on grain size. Coarse particles are easy to preserve while fine particles are easy to dissolve [11]. The $L$-ratio and HIRM have positive correlation in Units 1 and 2 (Figure 5(a)), which indicates that the sediment suffered different degrees of dissolution. However, samples in Unit 3 display variation of a linear trend first and then a stable trend. $L$-ratio shares an unclear correlation with HIRM which indicates samples in Unit 3 suffered weak dissolution, especially for those of $L$-ratio $>0.5$ [24]. The grain size of samples in Unit 1 is homogeneous (Figure 2(h) and (i)), with coarse PSD magnetite. The concentration of magnetite in Unit 2 is the lowest and the grain size become finer, with extremely low amounts of hematite. For Unit 3, typical weakly interacting SD magnetite exists, probably of biogenic origin [34]. Low temperature frequency-dependent susceptibility indicates the presence of an SP component (Figure 3(c)). HIRM increases upward which indicates that concentration of high coercivity magnetic minerals (e.g. hematite) increases, probably due to weakly oxic condition in the surface sediment, which is good for preservation of 3 -value iron oxides such as hematite.

\section{Discussion}

\subsection{Framework for paleoenvironmental variation of Nam Co}

Based on geochemical, sedimentological and microfossil analysis, Doberschütz et al. [19] suggested that both autochthonous carbonate precipitation, as mirrored by the calcium content and changing ostracod abundances, and the amount of minerogenic sediment influx, as represented by multiple elements ( $\mathrm{Ti}, \mathrm{K}, \mathrm{Al}, \mathrm{Rb})$, are assumed to reflect paleohydrological variations within the catchment, being directly linked to a strengthening or weakening of the Indian Ocean Summer Monsoon influencing Nam Co. Accordingly, the climatic changes of Nam Co area can be concluded as follows. A first strong monsoonal pulse is visible at $\sim 11.3 \mathrm{ka}$ cal BP, followed by colder and drier conditions up to $\sim 10.8 \mathrm{ka}$ cal BP. A warm and humid climate from $\sim 10.8$ to $\sim 9.5 \mathrm{ka}$ cal BP is related to a strong summer monsoon on the central TP, which triggers a prominent lake level rise. Declining rates of minerogenic input after $\sim 9.5 \mathrm{ka}$ cal BP indicates less moisture availability and hence a monsoonal weakening lasting up to $\sim 6.6 \mathrm{ka}$ cal BP. Afterwards, wetter conditions are inferred for the time span from $\sim 6.6$ to $\sim 4.8 \mathrm{ka}$ cal BP. A change towards drier conditions occurred after $\sim 4.8 \mathrm{ka}$ cal BP indicates lower summer monsoon intensity on the central TP, which further diminished after $\sim 2.0 \mathrm{ka}$ cal BP.

Compared to other lakes, the edge of south shore of Nam Co is steep (Figure 1), and Nam Co is supplied by rivers in the south. Therefore the distance between catchment and coring site varies only a small amount when the lake level varies significantly; also the path of detrital input from lake catchment varies little. What varies significantly is the grain size of detrital input. Therefore, lake level is associated with water dynamic conditions. When water supply is high, lake level increases, and water dynamic condition becomes stronger, the detrital input particles are accordingly coarse. In contrast, when water supply decreases, lake level decreases, and water dynamics condition becomes weaker, the detrital input particles become finer accordingly.

\subsection{Mechanism of variations in environmental magnetic proxies of lake sediments from Nam Co}

Doberschütz et al. [19] measured Ca content as a proxy for lake level, total organic carbon (TOC) as a proxy for initial productivity of lake, both proxies are closely related to
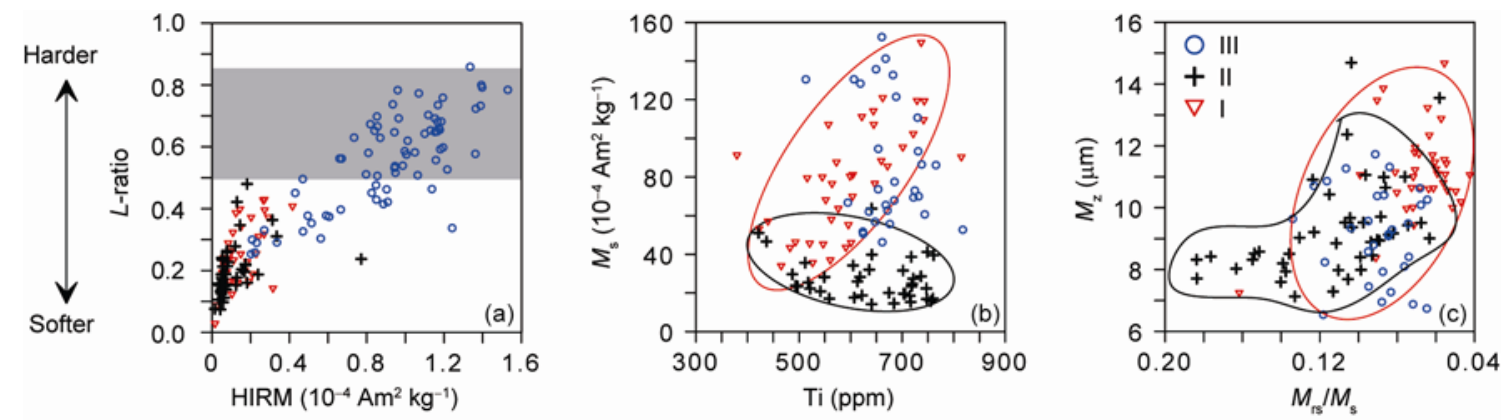

Figure 5 Correlation between HIRM and $L$-ratio (a), $M_{\mathrm{s}}$ and Titanium (b), $M_{\mathrm{z}}$ (mean grain size for bulk sample) and $M_{\mathrm{rs}} / M_{\mathrm{s}}(\mathrm{c})$ from core NC $08 / 01$ of Nam Co, Tibet, respectively. The shaded area indicates the samples suffering weak dissolution. 
redox condition in lake $[19,36]$. In this study we take content of Ti of lake sediments from Nam Co as the proxy for detrital input [19], $M_{\mathrm{s}}$ as the proxy for variations in magnetic mineral concentration, $M_{\mathrm{rs}} M_{\mathrm{s}}$ as the proxy for variations in magnetic mineral grain size (Figure 6) to elucidate the mechanism of variations in environmental magnetic proxies.

Susceptibility is low in the whole Holocene lake sediment $\left(\chi_{\mathrm{lf}}<12 \times 10^{-8} \mathrm{~m}^{3} \mathrm{~kg}^{-1}\right)$ for two reasons: on one hand, the water of Nam Co is mainly supplied from south and southwest shore mainly composed of sandstone, which contains less magnetic minerals and is weakly magnetic; on the other hand, there are probably iron sulfides in the whole core (probably greigite contained in coarse pyrite particles $[28,32,37])$, which is suggested by 3 -axis thermal demagnetization curves and $\chi$-T curves. This suggests that magnetic minerals are in reducing conditions. This is supported by the high TOC $(>1)$ which indicates that the lake bottom is probably anoxic [36]. Accordingly, some of the magnetic minerals are dissolved by reductive dissolution processes, which leads to low magnetism as a whole [11]. In lake depositional condition, redox process is controlled by several factors, including lake level, sedimentary rate, organic matter content, available contents of $\mathrm{Fe}$ and S [38], grain size and type of magnetic minerals [39,40]. For example, water level and water stratification in lake intensely influence the lake environments and furthermore the preservation of magnetic minerals. Williamson et al. [41] studied the lake sediment in a tropical maar lake in Madagascar and suggested that during dry period, when water level dropped, high coercivity magnetic minerals (hematite, goethite) were preserved preferentially, while they were dissolved in stratified deep water. In this study the discrepancies in the water dynamics of Nam Co since Holocene cause different grain sizes of input minerals, which results in corresponding different degrees of dissolution, finally causing significant discrepancies in magnetic minerals among different units. Therefore, degree of reductive dissolution of magnetic minerals is the main factor that influences the magnetic properties of lake sediment from Nam Co since Holocene and its response to climatic changes. The details are shown as follows.

For Unit $1(11.3-7.8 \mathrm{cal} \mathrm{ka} \mathrm{BP}) M_{\mathrm{s}}$ and Ti display a positive correlation (Figure 5(b)), and relatively coarse PSD magnetite dominates magnetic minerals (Figure 4(d)), which indicates that magnetic minerals are mainly of detrital input. Therefore $M_{\mathrm{s}}$ can reflect the signal of allochthonous input. In this period, TOC is the highest (Figure 6) which implies that the lake bottom is in strongest reducing conditions, while the high energy water transported detrital input particles are coarse due to strong water dynamics

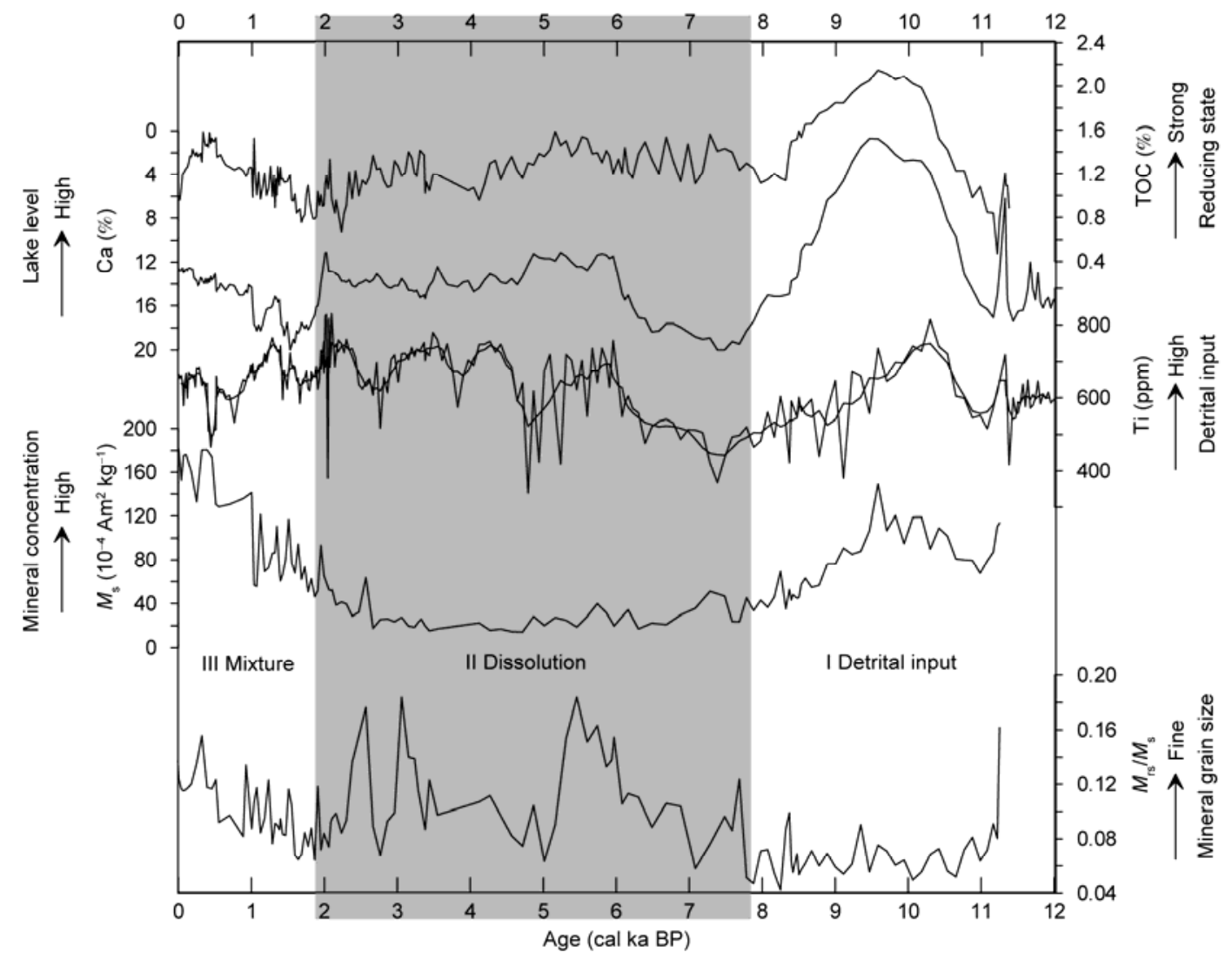

Figure 6 Variation of total organic carbon (TOC), calcium, titanium, $M_{\mathrm{s}}$ and $M_{\mathrm{rs}} / M_{\mathrm{s}}$ of sediment core NC 08/01 from Nam Co, Tibet. Titanium is smoothed by 5 -point running average. TOC, Ca and Ti data are (from unpublished data of Doberschütz S). 
inferred by the high lake level. Previous studies show that rate of reductive dissolution is influenced by ratio of surface to volume of particles [11]: Coarser-grained magnetite is harder to dissolve. Therefore, although the sediments of this unit are in strongly reducing conditions, the particles are so coarse that they were preserved well. So the magnetic parameters in the unit mainly reflect the signal of allochthonous input.

The grain size of magnetite in Unit 2 (7.8-2.1 cal ka BP) become finer, $M_{\mathrm{s}}$ is the lowest, concentration of Ti is relatively high as a whole, $M_{\mathrm{s}}$ show a negative correlation with Ti (Figures 5(b) and (6)), which is unrelated to signal of detrital input. Doberschütz et al. [19] suggested that as the Holocene Megathermal of Nam Co terminated since $\sim 8$ cal ka BP, precipitation caused by monsoon decreases, the glacial-melt water also decreases as temperature become colder. Concentrations of $\mathrm{Ca}$ started to rise after 7.5 cal ka BP, which indicates that the lake level decreases (Figure 6). This also implies that the water dynamics became weaker, and the particles fed into the lake become finer. Meanwhile, TOC decreased slightly, but remained relatively high value $(>1)$, which indicates that reducing conditions were relatively strong. Fine-grained magnetite is susceptible to reductive dissolution and dissolved significantly, which leads to weak magnetism and resulted in a negative correlation between $M_{\mathrm{s}}$ and $\mathrm{Ti}$ [42]. On the correlation plot of grain size for bulk samples and magnetic minerals (Figure 5(c)), grain size of bulk samples $M_{\mathrm{z}}$ in Unit 2 is stable (between 7-10 $\mu \mathrm{m})$, while the parameter $M_{\mathrm{rs}} / M_{\mathrm{s}}$, which reflects grain size of magnetic minerals have large fluctuations. This is indicative of significant postdepositional dissolution of magnetic minerals during this period. In addition, Zhu et al. [3] suggested that during 6.9-2.9 cal ka BP, Fe/Mn content of the lake sediment was relatively high. This indicates that this unit is in relatively strong reducing conditions. Therefore, although there are fluctuations of lake level during 11.3-2.1 cal ka BP, the lake is in reducing conditions as a whole due to the relatively high lake level. This causes dissolution of most of the detrital magnetic minerals and neoformation of authigenic iron sulfides (Figure 3(i), (j) and (o)). Therefore magnetic parameters in this unit mainly indicate the prevalence of redox conditions in the lake.

For Unit 3 (2.1-0 cal ka BP), $M_{\mathrm{s}}$ increases (Figure 6) without obvious correlation with $\mathrm{Ti}$ (Figure 5(b)), which suggests that magnetic enhancement is not dominated by detrital input. Several studies show that climate of Nam Co area became colder and drier since the late Holocene $[18,43]$. The abundance of ostracods is high and decreases slowly since 2.4 cal ka BP, which indicates that lake level become shallower first and then become deeper. The lake bottom is in weakly oxic environment with very weak dissolution processes, so ostracods can be preserved well [19]. Another reason for the enhanced magnetism in this period is that there is relatively abundant biogenic magnetite (Figures 3(b) and 4(a)). Biogenic magnetite has been reported in many lakes [44], which generally appear above $50 \mathrm{~cm}$ sediment depth and will slowly dissolved with depth, and were also influenced by redox boundary. Biogenic magnetite and hematite can be preserved well because of the weakly oxic condition in this period [41]. Hematite is obviously present in Unit 3 according to 3 -axis thermal demagnetization experiments, while hematite is almost completely dissolved in Units 1 and 2 due to the strong dissolution processes. In conclusion, the magnetic signal of this unit is dominated by mixture of biogenic magnetite and detrital magnetic minerals, which causes enhanced magnetism and reflecting oxic depositional condition.

\section{Conclusion}

Although magnetic properties of lake sediment are influenced by many factors, detrital input, reductive dissolution process and postdepositional magnetotactic bacteria activity can be distinguished by detailed rock magnetic study. Our study shows that the preservation of magnetic minerals is not only related to reducing conditions, but also the initial grain size of magnetic minerals. During 11.3-7.8 cal ka BP, extensive erosion of minerogenic minerals accumulated since last glacial period terminated. Lots of detrital magnetic minerals were fed into the lake and could be preserved well due to their coarse grain sizes although they were in reducing conditions. During 7.8-2.1 cal ka BP, climate shifts resulted in less water supply and the corresponding detrital particles become finer, suffering severe reductive dissolution. No detrital input signal was preserved. During 2.1-0 cal ka BP, when the lake conditions transforms to oxic conditions, the detrital magnetic minerals combined with biogenic magnetite are preserved well. In conclusion, magnetic parameters of Nam Co are sensitive to environmental changes and can provide detailed information on environmental changes and reductive dissolution processes. This study provides foundation for the interpretation of magnetic properties of the lake sediments in this area.

This work was supported by the National Natural Science Foundation of China (40874033, 41074041 and 41130529). We thank the two anonymous reviewers for their beneficial comments and suggestions. The authors thank Guoqiang Chu, Zhifeng Liu and Jianbao Liu for their helpful discussions.

1 Qiu J. The third pole. Nature, 2008, 454: 393-396

2 Gasse F, Arnold M, Fontes J C, et al. A 13000-year climate record from western Tibet. Nature, 1991, 353: 742-745

3 Zhu L P, Wu Y H, Wang J B, et al. Environmental changes since 8.4 ka reflected in the lacustrine core sediments from Nam Co, central Tibetan Plateau, China. Holocene, 2008, 18: 831-839

4 Bond G, Showers W, Cheseby M, et al. A pervasive millennial-scale cycle in North Atlantic Holocene and glacial climates. Science, 1997, 278: 1257-1266

5 Evans M E, Heller F. Environmental Magnetism: Principles and Applications of Environmagnetics. New York: Academic Press, 2003 
6 Tudryn A, Tucholka P, Gibert E, et al. A late Pleistocene and Holocene mineral magnetic record from sediments of Lake Aibi, Dzungarian Basin, NW China. J Paleolimn, 2010, 44: 109-121

7 Thouveny N, Debeaulieu J L, Bonifay E, et al. Climate variations in Europe over the past $140 \mathrm{kyr}$ deduced from rock magnetism. Nature, 1994, 371: 503-506

8 Zhu L P, Zhang P Z, Xia W L, et al. 1400-year cold/warm fluctuations reflected by environmental magnetism of a lake sediment core from the Chen Co, southern Tibet, China. J Paleolimn, 2003, 29: 391-401

9 Mischke S, Zhang C J. Holocene cold events on the Tibetan Plateau. Glob Planet Change, 2010, 72: 155-163

10 Mann S, Sparks N H C, Frankel R B, et al. Biomineralization of ferrimagnetic greigite $\left(\mathrm{Fe}_{3} \mathrm{~S}_{4}\right)$ and iron pyrite $\left(\mathrm{FeS}_{2}\right)$ in a magnetotactic bacterium. Nature, 1990, 343: 258-261

11 Jelinowaska A, Tucholka P, Wieckowski K. Magnetic properties of sediments in a Polish lake: Evidence of a relation between the rockmagnetic record and environmental changes in Late Pleistocene and Holocene sediments. Geophys J Int, 1997, 129: 727-736

12 Hu S Y, Wang S M, Appel E, et al. Environmental mechanism of magnetic susceptibility changes of lacustrine sediments from Lake Hulun, China (in Chinese). Sci China Ser D-Earth Sci, 1998, 28: 334-339

13 Stockhausen H, Thouveny N. Rock-magnetic properties of Eemian maar lake sediments from Massif Central, France: A climatic signature? Earth Planet Sci Lett, 1999, 173: 299-313

14 Wang L Q, Yi C L, Schütt B, et al. Genetic characteristics and environmental implications of sedimentary deposits of Lake Nam Co in Tibetan Plateau (in Chinese). Acta Sedimentol Sin, 2009, 3: 503-510

15 Frenzel P, Wrozyna C, Xie M P, et al. Palaeo-water depth estimation for a 600-year record from Nam Co (Tibet) using an ostracod-based transfer function. Quat Int, 2010, 218: 157-165

16 Keil A, Berking J, Mügler I, et al. Hydrological and geomorphological basin and catchment characteristics of Lake Nam Co, SouthCentral Tibet. Quat Int, 2010, 218: 118-130

17 Lin X, Zhu L P, Wang Y, et al. Environmental changes reflected by $n$-alkanes of lake core in Nam Co on the Tibetan Plateau since $8.4 \mathrm{ka}$ BP. Chin Sci Bull, 2008, 53: 3051-3057

18 Zhu L P, Peng P, Xie M P, et al. Ostracod-based environmental reconstruction over the last 8400 years of Nam Co on the Tibetan Plateau. Hydrobiologia, 2010, 648: 157-174

19 Doberschütz S, Daut G, Haberzettl T, et al. Reconstruction of Late Glacial paleo-monsoon dynamics using lacustrine sediments of Lake Nam Co, Tibetan Plateau, China. In: American Geophysical Union, Fall Meeting 2010, Abstract \# GC41A-0887, 2010 AGUFMGC 41A0887D

20 Wang J B, Zhu L P, Daut G, et al. Investigation of bathymetry and water quality of Lake Nam Co, the largest lake on the central Tibetan Plateau, China. Limnology, 2009, 10: 149-158

21 Guan Z H, Chen C Y, Ou Y X, et al. Rivers and Lakes in Tibet (in Chinese). Beijing: Science Press, 1984. 176-182

22 Zhu D G, Meng X G, Zhao X T, et al. On the Quaternary Environmental Evolution of the Nam Co Area, Tibet (in Chinese). Beijing: Science Press, 2004. 13-17

23 Kasper T, Haberzettl T, Doberschütz S, et al. Indian Ocean Summer Monsoon (IOSM)-dynamics within the past $4 \mathrm{ka}$ recorded in the sediments of Lake Nam Co, central Tibetan Plateau (China). Quat Sci Rev, 2012, 39: 73-85

24 Liu Q S, Roberts A P, Torrent J, et al. What do the HIRM and S-ratio really measure in environmental magnetism? Geochem Geophys Ge- osys, 2007, 8: Q09011

25 Roberts A P, Pike C R, Verosub K L. First-order reversal curve diagrams: a new tool for characterizing the magnetic properties of natural samples. J Geophys Res, 2000, 105: 28461-28475

26 Harrison R J, Feinberg J M. FORCinel: An improved algorithm for calculating first-order reversal curve distributions using locally weighted regression smoothing. Geochem Geophy Geosy, 2008, 9: Q05016

27 Liu Q S, Deng C L, Yu Y J, et al. Temperature dependence of magnetic susceptibility in an argon environment: Implications for pedogenesis of Chinese loess/palaeosols. Geophys J Int, 2005, 161: 102- 112

28 Lowrie W. Identification of ferromagnetic minerals in a rock by coercivity and unblocking temperature properties. Geophys Res Lett, 1990, 17: 159-162

29 Roberts A P, Pillans B J. Rock magnetism of lower/middle Pleistocene marine sediments, Wanganui Basin, New Zealand. Geophys Res Lett, 1993, 20: 839-842

30 Roberts A P. Magnetic properties of sedimentary greigite $\left(\mathrm{Fe}_{3} \mathrm{~S}_{4}\right)$. Earth Planet Sci Lett, 1995, 134: 227-236

31 Verwey E J. Electronic conduction of magnetite $\left(\mathrm{Fe}_{3} \mathrm{O}_{4}\right)$ and its transition point at low temperature. Nature, 1939, 144: 327-328

32 Roberts A P, Chang L, Rowan C J, et al. Magnetic properties of sedimentary greigite $\left(\mathrm{Fe}_{3} \mathrm{~S}_{4}\right)$ : An update. Rev Geophys, 2011, 49: RG1002, doi: 10.1029/2010RG000336

33 Özdemir Ö, Dunlop D J. Hallmarks of maghemitization in lowtemperature remanence cycling of partially oxidized magnetite nanoparticles. J Geophys Res, 2010, 115: B02101

34 Li J H, Pan Y X, Chen G J, et al. Magnetite magnetosome and fragmental chain formation of Magnetospirillum magneticum AMB-1: Transmission electron microscopy and magnetic observations. Geophys J Int, 2009, 177: 33-42

35 Dunlop D J. Theory and application of the Day plot $\left(M_{\mathrm{rs}} / M_{\mathrm{s}}\right.$ versus $\left.H_{\mathrm{cr}} / H_{\mathrm{c}}\right)$. 1. Theoretical curves and tests using titanomagnetite data. J Geophys Res, 2002, 107, doi: 10.1029/2001JB000486

36 Nowaczk N R, Harwart S, Melles M. A rock magnetic record from Lama Lake, Taymyr Peninsula, northern Central Siberia. J Paleolimn, 2000, 23: 227-241

37 Nowaczyk N R. Dissolution of titanomagnetite and sulphidization in sediments from Lake Kinneret, Israel. Geophys J Int, 2011, 187: 3444

38 Berner R A. Sedimentary pyrite formation: An update. Geochim Cosmochim Acta, 1984, 48: 605-615

39 Canfield D E, Raiswell R, Bottrell S. The reactivity of sedimentary iron minerals toward sulfide. Am J Sci, 1992, 292: 659-683

40 Poulton S W, Krom M D, Raiswell R. A revised scheme for the reactivity of iron (oxyhydr)oxide minerals towards dissolved sulfide. Geochim Cosmochim Acta, 2004, 68: 3703-3715

41 Williamson D, Jelinowska A, Kissel C, et al. Mineral-magnetic proxies of erosion/oxidation cycles in tropical maar-lake sediments (Lake Tritrivakely, Madagascar): Paleoenvironmental implications. Earth Planet Sci Lett, 1998, 155: 205-219

42 Berner R A. Early Diagenesis: A Theoretical Approach: Princeton University Press, 1980

43 Li Q, Lu H Y, Zhu L P, et al. Pollen-inferred climate changes and vertical shifts of alpine vegetation belts on the northern slope of the Nyainqentanglha Mountains (central Tibetan Plateau) since $8.4 \mathrm{kyr}$ BP. Holocene, 2011, 21: 939-950

44 Egli R, Chen A P, Winklhofer M, et al. Detection of noninteracting single domain particles using first-order reversal curve diagrams. Geochem Geophys Geosys, 2010, 11: Q01Z11

Open Access This article is distributed under the terms of the Creative Commons Attribution License which permits any use, distribution, and reproduction in any medium, provided the original author(s) and source are credited. 